\title{
POESÍA NO DICE NADA: UNA APROXIMACIÓN AL RITMO SEMÁNTICO
}

\section{Helena Usandizaga}

\author{
Universidad Autónoma de Barcelona
}

\begin{abstract}
La poesía es una enunciación que ninguna paráfrasis puede agotar, pues la poesía no trata de ideas sino de la música del azar. La poesía proclama que hay algo más real que las ideas, algo que permanece, por así decirlo, siempre obstinadamente informulado, pero que nosotros como lectores de poesía no tenemos problemas en experimentar y saborear en los poemas que amamos. Para mí, las imágenes y las metáforas, lo que vemos y lo que imaginamos, su perpetuo socavamiento mutuo, su paradoja, su ambigüedad, su condición ladina, su deslumbrante sabiduría y comedia, llegan al meollo de nuestra existencia, pues nuestra existencia, también ella, no puede ser parafraseada (palabras de Charles Simic en Wright, 1998: 147).
\end{abstract}

Llevando la idea de lo informulado a sus últimas consecuencias, dice también el poeta peruano Martín Adán que «Poesía no dice nada/ Poesía se está callada/escuchando su propia voz» ${ }^{1}$. Pero lo cierto es que nos empeñamos en traducir el poema: en buena parte, la crítica

1 Estos versos pertenecen al libro La piedra absoluta, de 1966. 
poética podría verse como una corriente paralela de lecturas - no infinitas ${ }^{2}$ - que enriquecen y precisan la nuestra, y en este sentido no se trata de descalificarlas. Más bien, el problema que se plantea aquí es el de la incomplección y, a veces, el del exceso de estas lecturas racionalizadoras y narrativizadoras de lo poético. El poema no es una adivinanza, ni es tampoco solamente un tejido de referencias cultas que basta con conocer, aunque a veces lo oculto o la propia tradición ayuden a su comprensión. Más que la idea, lo que se percibe en un poema, lo que lo hace significativo y diferente a otros, es cierto tipo muy peculiar de tensión o de contradicción interna. Y esto es importante especialmente en el poema moderno, cada vez más «roto» en relación con la noción de armonía entre el hombre y el universo, o con la noción de la adecuación entre el lenguaje y la intuición poética. Esta tensión y esta contradicción no se presentan, además, como algo dado, sino como un trayecto que se propone al lector para que se inscriba en un ritmo y en un tono particulares de ese poema. Leer el poema desde la crítica es entonces, también, hablar de esto. Ballart (1998), por ejemplo, parte de la idea de que «lo sustantivo en toda poesía viene a ser una resolución de tensiones» (145), para recoger las ideas de Richards sobre el tono, y su distinción entre "poética de la tensión» y «poesía de síntesis» (148), y también las de Culler sobre los «operadores temáticos» relacionados con la ambivalencia, la ambigüedad, la paradoja, la tensión (149), así como los cambios de nivel que sustentan el significado poético (152); del mismo modo, señala que Culler, al criticar el New Criticism y su método de exégesis del poema, reclama «dar explicación a la encrucijada de significados por los que se veían discurrir los poemas...» $(162)^{3}$. El poema no necesariamente tiene un final de resolución o de clausura, pues, en efecto, la tensión no llega siempre a ser resuelta; pero ella es, sin duda, uno de los rasgos definitorios del poema. A veces, la forma, no necesariamente armónica, es sustituto de la resolución, y lo que dice esta sustitución es la radical imposibilidad de conciliar los contrarios, la búsqueda de unidad y la imposibilidad de alcanzarla; otras veces, la resolución es fugaz; otras veces, esa resolución se da brillantemente, como en el fin de una pieza musical. Pero

2 Este punto de partida - - el de la dificultad de traducción de la poesía- no implica que el poema acepte cualquier lectura, ni menos que signifique cualquier cosa. Más bien se trata de leer el poema desde «otro lugar» de percepción, pero no desde la indeterminación.

${ }^{3}$ Esta encrucjada, para nosotros, no es ilimitada. Tal como señalábamos antes, las lecturas no son infinitas. Más bien creemos, con Eco (1979), que el lector sigue el trayecto que configura el texto, y que el lector modelo que el texto dibuja supone una cierta demarcación del sentido. 
siempre que el poema es logrado, es cierto, las tensiones se convierten en sistema rítmico, en trayecto que nuestro cuerpo seguirá, en el propio tejido del poema.

Hay gran cantidad de testimonios de poetas (Poe, Maiakoski, Ungaretti, Ferrari, Eielson, Rilke...) que, preguntados por la génesis del poema, aluden a una materialidad que golpea, jadea o martillea en su interior, o a una frase que pide continuidad; como si lo más importante del poema fuera ese ritmo profundo que configurará sus tensiones, y que tanto tiene que ver con el tono del poema. Llevando este punto de partida a sus últimas consecuencias, encontramos algo así como un modo de conocimiento: con ello, no pretendemos establecer una definición esencial de la lírica, pero sí detectar un modo que históricamente se ha constituido en una línea muy importante de la poesía. José Ángel Valente (1998) reconoce ese modo como «una experiencia espiritual profunda» (55), un conocimiento «que ciertos autores han llamado aparicional o presentacional, al que se llega por una especie de revelación, no por una cadena de enunciados» (56); para él, en un esquema de viaje iniciático, ocurre que «en el descenso más absoluto la palabra poética llega a la memoria de la materia. Entonces la palabra poética no versa sobre la materia sino que es materia; no versa sobre el cuerpo, es cuerpo. Esa fase, para mí, estaría regida por el primado del eros» (54). De una manera general, y no sólo referida a este modo, parece que se puede hacer una analogía entre la percepción del sentido del poema y las percepciones rítmicas, entendidas como expectativas que se cumplen o se frustran; incluso con lo más material de las percepciones rítmicas, que remiten a las del propio cuerpo. En el poema, el ritmo más evidente es el ritmo sonoro, pero lo que reclamamos es una concepción más profunda del ritmo como ligado al tono $y$, en última instancia, al significado.

Otro poeta peruano, César Vallejo ${ }^{4}$ (1973: 69), asegura en este sentido que «todos sabemos que la poesía es intraductible. La poesía es tono, oración verbal de la vida. Es una obra construida de palabras. Traducida a otras palabras, sinónimas, pero nunca idénticas, ya no es la misma. Una traducción es un nuevo poema, que apenas se parece al original». Para Vallejo, en efecto, «lo que importa principalmente en un poema es el tono con que se dice una cosa $y$, secundariamente, lo que se dice»; se pueden traducir los poetas que trabajan con ideas, pero

\footnotetext{
${ }^{4}$ Este artículo fue escrito entre 1929 y 1939 . Vallejo fecha su corrección en 1932 y 1934.
} 
no, piensa Vallejo, los mejores, los que trabajan con el tono, con el «ritmo cardíaco de la vida»; de Walt Whitman, por ejemplo, sólo se traducen las grandes ideas, «pero no se traduce los grandes movimientos animales, los grandes números del alma, las oscuras nebulosas de la vida, que residen en un giro del lenguaje, en una tournure, en fin, en los imponderables del verbo» (70).

Si a los poetas les interesan tanto «los grandes números del alma», ¿por qué se trabaja relativamente poco con la construcción rítmica y tonal del poema? Resulta quizás más satisfactoria, y es además necesaria, la lectura que abre puertas conceptuales y culturales a la comprensión del poema, pero, como dijimos, tiene sus peligros y limitaciones. Hay, por supuesto, estudios métricos centrados en el plano de la expresión, pero menos abundantes son los centrados en el plano del contenido. Ritmo, tono, entonación, respiración: todos estos conceptos entran en juego cuando queremos enfrentarnos al poema de un modo diferente al puramente exegético. Algunas aproximaciones, a pesar de no ser numerosas, son ya clásicas en los estudios de poesía en lengua española; baste el ejemplo del trabajo de Amado Alonso sobre la poesía de Neruda: al encontrarse con una versificación que no es analizable con los instrumentos clásicos, recurre a las reiteraciones y fluctuaciones del sentido para explicar el resultado rítmico del poema. Encontramos tentativas aquí y allá: en otro sentido, Herrnstein Smith (1968) propone un largo e interesante estudio sobre la distribución del sentido en el poema; de hecho, existe una tradición de estudio del tono en la poesía en lengua inglesa, y a menudo se recurre a la definición de tono que dan Brooks y Penn Warren — «el tono del poema indica la actitud del hablante hacia su sujeto y hacia su público y, a veces, hacia sí mismo»- (ver por ejemplo Mangini González, 1979: 74, quien a partir de esta cita hace interesantes observaciones sobre el tono en poemas de Gil de Biedma). Hay otras propuestas apuntadas, como las anteriormente mencionadas de Culler, o la muy sugerente de Rowe, quien trabaja a partir del concepto de entonación, el cual sería a la vez trasunto de un tono social, ritmo de la conversación y ritmo del cuerpo. También Meschonnic (1982) recorre el problema del ritmo, profundizando en el de la expresión, aunque discute algunas extensiones de los conceptos de ritmo y respiración ${ }^{5}$. Pero hay seguramente razo-

5 La relación entre ritmo y percepción corporal es generalmente aceptada, pero Meschonnic (1982) llama la atención sobre los abusos de un uso poco reflexivo de los términos. Meschonnic (1982: 654) reconoce que el ritmo es algo «ligado al cuerpo, (...) 
nes por las cuales estos estudios no se hacen sistemáticos: una, relativa a la confusión entre los términos y a la falta de base teórica; y otra, que tiene que ver con el mismo desarrollo de los estudios poéticos.

\section{EL RITMO Y EL TONO EN LA TEORÍA DEL DISCURSO POÉTICO}

El estudio del ritmo tiene, es verdad, un lugar importante en la historia de la teoría del discurso poético. Pero si la observamos en perspectiva, esta historia resulta mucho más accidentada que la del discurso narrativo o de las estructuras narrativas en general; no se puede negar, sin embargo, que un punto de referencia, aunque discutible y discutido, siguen siendo los principios de Jakobson. La idea -insatisfactoria - de repetición está ligada a su definición de la función poética: «la función poética proyecta el principio de equivalencia del eje de la selección sobre el eje de la combinación» (1963: 220). De hecho, el mismo Jakobson, en algunos textos (por ejemplo, 1980), ha insinuado ya una dimensión más compleja en relación con la repetición del verso y las variaciones que se unen a la invariante de la medida. Pero muchos trabajos que apuntan nuevas direcciones están todavía hoy ligados a la crítica a esta idea de un principio de organización exclusivamente paradigmático del discurso poético, ya cuestionada por Greimas (1972) y Coquet (1972).

En efecto, el principal equívoco que alimenta la idea de la organización paradigmática del poema es el de un concepto de ritmo que olvida el sentido de tensión, de dirección, para limitarse a explicar la aparición de elementos repetidos según un mismo esquema. Entre las proposiciones que cuestionan fructíferamente este principio están las de Zilberberg (1988), las cuales tienden a establecer, en este mismo senti-

\footnotetext{
ejercido por nuestro cuerpo», pero comenta críticamente la tradición que ha producido metáforas de esos intercambios entre lo corporal y el lenguaje (tradición en la que se encuentran títulos clásicos como los de Spire, 1949; Fraisse, 1956; Tomatis, 1978). Para Meschonnic, la voz, y no la respiración, es la materia de la oralidad; por eso rechaza el aliento como metáfora de lo métrico y como portador o dotado de signos. En el mismo sentido, propone distinguir lo cultural del ritmo del universal del cuerpo que es la respiración (660). Sin embargo, a mi parecer, cabría mantener la respiración en el otro sentido de metáfora de los avatares rítmicos del plano del contenido, y, tal como veremos, la semiótica ha razonado este aspecto.
} 
do, un comercio entre direcciones e instantes (133); es decir, a superar la simple comprensión, propiciada por la «función poética» de Jakobson, de cómo una singularidad toma forma en un determinado punto de la cadena, y a desentrañar, en cambio, cómo se establece el lazo entre un determinado accidente local, intenso, y un determinado dato semántico extenso, es decir, coextensivo del poema. Reconociendo, con Hjelmslev, unas mismas relaciones al plano de la expresión y al del contenido, Zilberberg (99-100) pone en paralelo la categoría de carácter demarcativo tensión/laxitud (que marca una directividad) y la categoría de carácter segmentativo extenso/intenso (que aspectualiza la cadena). De ahí, también, su uso del concepto de «saillance» para lo intenso (local) y de «passance» para lo extenso (global, que articula la cadena).

En efecto, para Zilberberg (133-140), aparte del problema de que la función poética desborde para Jakobson el dominio poético, la principal dificultad -que se deriva igualmente del binarismo estrecho cultivado por Jakobson- está en que las características de esa función suponen que todas las secuencias deben depender de un mismo principio y que éstas están en relación de equivalencia entre sí, que son «reiteración regular de unidades equivalentes» en el poema. Se postula una equivalencia paradigmática, pues, que hace imposible establecer gradaciones en un organismo como el poema, que no es repetición, ni siquiera sucesión de estados discontinuos ${ }^{6}$, sino proceso figurativo aspectualizado en relación con un horizonte de tensión con el que juega.

Zilberberg introduce en su trabajo un acercamiento rítmico a la tensividad, a la dirección, y desecha el puramente métrico, basado en la repetición de unidades equivalentes. Se trata, pues, de dar cuenta de la aspectualidad que introduce la secuencia en su aspecto demarcativo, y no solamente de la segmentación (138), elucidando así la dirección rítmica y tonal del poema. En este sentido parecen ir también las intuiciones de Paz (1956: 56-57) sobre el ritmo:

Aun reducido a este esquema, el ritmo es algo más que medida, algo más que tiempo dividido en porciones. La sucesión de golpes y pausas revela

6 Hay que anotar que, de todas maneras, el análisis debe partir de la discontinuidad, de la segmentación, para relacionarla luego con la globalidad del poema. Las bases metodológicas del análisis que aquí se propone se encuentran en Greimas y Courtés (1979), Greimas y otros (1986) y, en especial, en Greimas (1986). 
una intencionalidad, algo así como una dirección. El ritmo provoca una dirección, suscita un anhelar. Si se interrumpe, sentimos un choque (...). Asi pues, el ritmo no es exclusivamente una medida vacía de contenido, sino una dirección, un sentido. El ritmo no es medida, sino tiempo original.

Así, el acercamiento semiótico parece ser, curiosamente, el más cercano a muchas intuiciones de los poetas y a la preocupación por poner de relieve la tensión rítmica y perceptiva del poema, análoga a una pieza musical con la que transcurrimos porque nos lleva hacia algo; por otro lado, como veremos, la semiótica ha explorado la posibilidad de estudiar el ritmo del plano del contenido, y no sólo el del plano de la expresión.

\section{POESÍA Y PERCEPCIÓN: LO SENSIBLE DEL SENTIDO}

Pues, por extraño que parezca, la semiótica, a veces vista como un análisis mecanicista y abstracto, se ha planteado los problemas del sentido que afectan al discurso poético. Interrogarse semióticamente sobre el discurso poético equivale a interrogarse sobre la dimensión estética y pasional, sobre una apariencia que hace posible el conocimiento y la significación; a preguntarse cómo las tensiones y distensiones de cada poema conforman su propia tensividad, su ritmo y su tono peculiares, basados, en última instancia, en la mediación perceptiva del cuerpo. De un modo general, la importancia de lo sensible y de lo sensitivo - de la percepción y del sentir- en la emergencia y el mantenimiento del sentido se viene señalando desde diversos ángulos semióticos. Fontanille (1998), por ejemplo, sintetiza el problema (1998), pero ya antes (1992: VI) se había referido al lugar cada vez más importante que adquieren la percepción y la figuratividad en las investigaciones semióticas contemporáneas, y subrayaba la relación entre mundo natural y lengua natural establecida ya por Greimas y Courtés (1979: 233) ${ }^{7}$. Fontanille (1992) se refiere también a la importancia de la propioceptividad —del semantismo que resulta de

${ }^{7}$ Greimas se ha referido a este punto en otras ocasiones, pero es particularmente explícito sobre la relación entre la percepción y el sentido cuando dice que «hay que introducir relaciones semánticas proyectadas por el sujeto en el mundo para decir que el mundo es un lenguaje, y no una colección de objetos» (1987a: 324). 
la percepción por parte del hombre de su propio cuerpo- en su prólogo al estudio de Ouellet (1992), quien relaciona el sentido con lo sensible, la percepción y la ideación. En el último trabajo de Greimas, escrito en colaboración con Fontanille (1991: 12), se insiste en esta mediación del cuerpo, la propioceptividad, para transformar el mundo en sentido, en lengua; para interiorizar las figuras exteroceptivas y hacer posible que la figuratividad se considere como una manera de pensar del sujeto.

Las cosas son para estos autores mucho más radicales en el caso de las pasiones violentas (entusiasmo, cólera, desesperación), que, aun siendo un caso límite, pueden ponerse en relación con la creación artística y explican cómo se despliega la figuratividad en otras situaciones pasionales más «suaves»; en pasiones violentas como el entusiasmo, por ejemplo, hay una fractura que transforma en «otro» al sujeto. Entonces la pasión aparece como la negación de lo racional y de lo cognitivo, y el «sentir» desborda al «percibir» (18): ahora la propioceptividad ya no es una instancia de mediación entre lo exteroceptivo y lo interoceptivo, sino

la carne viva, la propioceptividad "salvaje» que se manifiesta y reclama sus derechos en tanto que «sentir» global. Ahora ya no es que el mundo natural vaya hacia el sujeto, sino que el sujeto se proclama amo del mundo, su significado, y lo reorganiza figurativamente a su manera. El mundo llamado natural es entonces un mundo para el hombre, un mundo que podríamos llamar humano $(18-19)^{8}$.

También Fabbri (1992: 21) recuerda cómo, para el propio Greimas, lenguas naturales y mundo natural no están separadas, sino entrelazadas como en un monograma; las categorías del significante del mundo son las mismas que las que constituyen el plano del contenido del lenguaje natural. Nos interesa especialmente cómo Fabbri (22-23), al comentar la conexión de Greimas con las ideas de Merleau-Ponty sobre la experiencia perceptiva, subraya la dimensión estética de la percepción y la variedad de sentidos que entran en juego en esta exploración previa a la representación conceptual. Esta prioridad sitúa a Greimas, según Fabbri, frente al intelectualismo y su versión actual, el cognitivismo; su misma valoración de lo tangible (y lo olfativo) frente a lo visual, por ejemplo, es un intento de dar cuenta de la totalidad,

${ }^{8}$ Todas las citas con referencia en francés han sido traducidas por mí. 
materialidad y sensualidad de la percepción y sobre todo de «la parábola de la pasión y de la acción» que explica a través del contacto la manera como el sujeto emerge al mundo. De modo parecido, la sinestesia se valoriza porque añade la virtualidad de sensaciones realizadas a un nivel imaginario; tactilidad y sinestesia están en el límite extremo de lo sensible desde donde se puede, dice Fabbri (22-23), intentar el salto que permite alcanzar a partir de la percepción (que inaugura el conocimiento) un modo de sentir articulado sobre la afectividad profunda. Para Fabbri (21-22), además, la manifestación de lo sensible como sentido es particularmente evidente en el poema, y esto apoya semióticamente lo anteriormente apuntado: antes que una idea, el poema es una voz, el ritmo, y una respiración, el tono; esa respiración patémica que tan difícil es no traicionar en la traducción ritmo y tono que son significativos, que se confunden y se mezclan, que se supeditan el uno al otro: no es posible interrogarse sobre el uno sin pensar en el otro.

Recientemente, Fontanille (1998: 216) considera el ritmo como «una de las formas mínimas de la intencionalidad», ya que la organización de las apariciones y desapariciones parece indicar un programa; para él «en donde hay ritmo, habría, por lo menos virtualmente, sentido» (216). Para él, también el ritmo se relaciona con el componente pasional y se define a partir de la percepción del propio cuerpo: «desde el punto de vista del efecto pasional, el ritmo es sobre todo el perfil de las tensiones experimentadas por el propio cuerpo: ritmo desacelerado, agitado, sincopado... que desacelera, agita o hace brusca la percepción propioceptiva» (216).

Teniendo en cuenta estas reflexiones semióticas, y puesto que el propósito del trabajo es llegar a alguna conclusión sobre el ritmo semántico, estrechamente ligado al tono, podríamos intentar definir a este último como la manifestación —rítmica en el poema- de la actitud del enunciador hacia su enunciado, y, por supuesto, también hacia el enunciatario y hacia sí mismo. Definición ciertamente intuitiva y muy ligada a la clásica antes mencionada, pero que permite trabajar para confirmar que la marca del tono, sin ser específica del poema, le es indispensable y se halla en él mucho más concentrada que en la mayoría de textos; y a la vez que el ritmo y el tono están inscritos en el poema como un trayecto de lectura. No se trata, por tanto, de dar una interpretación del poema (aunque al hablar de su tono nos encontraremos con su sentido), sino de ver qué trayectos nos hace recorrer. 


\section{RITMO DEL CUERPO, TONO PASIONAL}

Al interrogarnos sobre el ritmo, pues, hemos de volver a lo sensible, a lo propioceptivo como mediación. La relación directa del ritmo con la percepción corporal, es decir, de los movimientos regulares del cuerpo (sístole/diástole del corazón, inspiración/expiración, tensión/ distensión de las cuerdas vocales) con la construcción de la percepción rítmica es una vía abierta para la investigación, como anota Jacquemet en Greimas y otros (1986: 191). Según él, ampliando las relaciones entre semiótica y conocimiento biológico, la forma «ritmo» debería poderse llegar a reconocer a través de los universales semánticos del conocimiento.

Como decíamos, hasta ahora el ritmo se ha estudiado sobre todo a través del plano de la expresión, de los efectos rítmicos «materiales» $\mathrm{y}$ de su valor tonal y afectivo; en cuanto al ritmo semántico, se ha abordado en general de forma más intuitiva, pero parece que en este momento, con el estudio de las pasiones, se dispone de instrumentos más adecuados, que profundizan el análisis narrativo y discursivo necesario para detectar la posición del sujeto y los juegos discursivos que determinan la distancia enunciativa ${ }^{9}$; puesto que se trata de estudiar no sólo el componente pragmático y cognitivo, si no también el pasional de estos juegos. En este sentido, y recogiendo las cuatro vías de acceso principales a los efectos pasionales recogidas por Ouellet (1992), Fontanille (1992: VII) observa que la que hace referencia a la modulación rítmica de los recorridos discursivos se evoca principalmente a partir del plano de la expresión, pero se puede pensar, con $\mathrm{Cl}$. Zilberberg, especialmente, que si los esquemas prosódicos rigen y hacen significar a las variaciones de intensidad del plano de la expresión. se podría conceder el mismo papel a las pasiones en relación con el plano del contenido.

Dorra (1997) estudia estas relaciones entre la respiración, el cuerpo y el sentido (186-187), y observa cómo la frase misma se organiza según una tensión y distensión, en un ritmo como el de la respiración (188). Esta respiración, cuya unidad de metro «natural» correspondería a dos octosílabos (189), la relaciona con la entonación y, a la vez, con la cosmovisión del gaucho, en su estudio del ritmo profundo del

${ }^{9}$ Greimas (1987b) ha estudiado estos trayectos en su análisis de un poema de Rilke. 
Martín Fierro, de José Hernández ${ }^{10}$; ve así el ritmo verbal y respiratorio como organizador del sentido de la vida (191). Las fases ascendente y descendente corresponden a una fase proposicional y otra declarativa, y este sistema de oposiciones y de paralelismos tiende a reproducirse en el plano sintáctico y semántico. Esta doble duplicación de una unidad binaria según una progresión geométrica podría ser, según Dorra, la «forma a la que tienden las tensiones del «alma» colectiva» (193-194). Este esquema de relaciones opositivas «se mantiene en todos los estadios de un proceso que une la respiración a la voz, la voz a la entonación, la entonación a la memoria» (195). De modo más general, Dorra considera que la significación y en concreto la experiencia estética tienen lugar cuando lo sensible se hace forma (195196), y esto acontece en el cuerpo, pues el encuentro con el objeto hace cambiar el ritmo respiratorio (198); siguiendo a Greimas (1991, pero sobre todo 1987b), Dorra señala este encuentro excepcional como una alteración del ritmo respiratorio hasta llegar a su suspensión (199), de tal modo que este momento en que el sentido está a punto de entregarse en su plenitud no puede ser más que una inminencia y una promesa (200). Dorra propone una hipótesis que, según él, la semiótica podría explotar con provecho, y que va en el sentido de la relación entre significación y respiración que reivindicábamos:

Como muestra el análisis de los fenómenos prosódicos, las inflexiones de la respiración constituyen la vertiente perceptible de las inflexiones de la significación. Yendo desde la estética verbal hacia una estética general, se puede pensar que toda conversión de lo sensible en significación es un proceso que pone en juego las inflexiones constitutivas del ritmo respiratorio (201).

\section{LA MÚSICA DEL POEMA: ALGUNAS APROXIMACIONES SEMIÓTICAS}

La teoría semiótica, desde luego, no es el único modo de acceder a la comprensión de la música del poema; pero el propósito de este trabajo es preguntarse sobre algunos instrumentos que ésta proporciona.

\footnotetext{
${ }^{10}$ Para Dorra, pues, la respiración sí está ligada al ritmo del sentido, al contrario que para Meschonnic.
} 
Partiendo de las ideas de ritmo y tono hasta ahora esbozadas, parece evidente que, desde un punto de vista semiótico, estos efectos se producen en el plano de la enunciación, puesto que estamos hablando de un trayecto que el texto dispone para que sea seguido por un enunciatario, lo cual permite entender esa «respiración» tensiva del poema, es decir, la construcción de una dirección hecha de tensiones y distensiones. Del mismo modo que ocurre en el plano de la expresión, según Zilberberg (1988: 224), en el del contenido «el poema insinúa un orden, formulable como sistema y como proceso: como sistema, establece distancias y presenta tensiones; como proceso, las recorre y las resuelve».

Habría que preguntarse de nuevo si estos recorridos propuestos al lector son ilimitados, si cualquier percepción rítmica y tonal es posible en un determinado poema. La respuesta tiene que ver con la concepción de la lectura que cada teoría propone; en el caso de la semiótica de Eco y Greimas, desde luego, estos trayectos están determinados, a pesar de la posibilidad de varias lecturas. Sin embargo, para ambos autores, la posibilidad de estudiar la instancia de la enunciación se ve desde diferentes puntos de vista. Eco (1979) ha estudiado el conjunto de actividades semióticas de cooperación que todo texto exige de sus lectores para ser actualizado, y que coinciden con la actividad misma de dar sentido al texto. Eco cree que las aperturas del texto están marcadas, que no estamos ante una obra abierta a cualquier cosa, pero que las aperturas requieren esa actividad pragmática del lector. La teoría de Greimas, frente a esto, no habla de actividad pragmática, puesto que la semiótica greimasiana cree que no puede estudiarse directamente la instancia de la enunciación y que hay que hacerlo a partir de la enunciación enunciada; esto remite a un cierto inmanentismo de esta teoría, centrada en el texto. Sin embargo, hay que recordar que para la escuela greimasiana, texto es todo aquello significativo que se necesita para desentrañar un significado, lo que hace que, a pesar del inmanentismo, no se separe la significación de un texto del componente social y cultural. La construcción del significado es una actividad intersubjetiva y cultural, que pone en juego múltiples discursos. Por ejemplo, Greimas (1984) ha estudiado las redes de lectura que propone un texto plástico y Fontanille (1987) ha trabajado teniendo en cuenta la distribución del saber en el texto, de tal modo que puede suponerse cómo los actantes de la enunciación lo toman a su cargo. La enunciación es así un presupuesto lógico del enunciado, pero, en el momento actual, la teoría, al menos en algunas de sus versiones, no se limita a estudiar el sujeto enunciador definido por el yo-ahora-aquí y el sujeto enunciatario pro- 
puesto por este último o presupuesto por la operación de interpretación del texto, sino algo así como una estrategia global, un proceso enunciativo que podemos reconstruir a partir de unas marcas en el texto y que podemos estudiar con los mismos instrumentos que usamos para el enunciado, aunque sin confundir esta instancia con una «representación» de la enunciación.

Qué duda cabe de que el estudio del enunciado sirve para detectar ese trayecto, puesto que el escenario que es la enunciación enunciada - con su ego, hic et nunc- y los afectos «desembragados» en el enunciado son los que permiten estudiar el embrague enunciativo ${ }^{11}$. Esta dimensión está, pues, directamente relacionada con la posición del sujeto y su situación en el tiempo y el espacio, y los juegos discursivos que esta disposición produce, así como el trayecto que esto supone para un hipotético enunciatario. Pero no se trata sólo de estudiar la disposición del saber que configuran los recorridos narrativos y discursivos, sino de trabajar también con el componente modal que rige las pasiones del texto. Para Fontanille, las pasiones y el ritmo, la determinación modal y la determinación tensiva, están estrechamente relacionados (una relación que compara con la de los fonemas y la entonación, 200); él habla de «ritmos pasionales» (204); y dice que «los esquemas tensivos del discurso conjugan en todos sus escenarios un grado de intensidad y un grado de cantidad. Lo propio de la racionalidad pasional es conjugar gradientes y hacer nacer tensiones» (208). Según esto, no detectamos las pasiones léxicamente, sino porque conjugan lo sensible (códigos somáticos y figurativos) y lo inteligible (códigos modales, perspectivos y rítmicos). En este sentido, hemos hablado de dos componentes estudiados por la semiótica que podrían guiar el estudio de estos trayectos: en primer lugar, la distancia enunciativa, es decir, los juegos que se establecen a partir del ego, hic et nunc; en segundo lugar, las variaciones en la tensión que hacen de la estructura del poema no una repetición, sino un proceso, y que están estrechamente ligadas al componente pasional, si bien en primera instancia se configuran como una disposición de isotopías; a través de estas instancias emerge un plano de tensividad profunda que manifiesta la modulación pasional. Lo perceptivo, lo pasional y lo rítmico se conjugan, pues, en el estudio del discurso poético que busca dar un atisbo de esos trayectos enunciativos. Tres son los caminos semióticos: el estudio de la enunciación enunciada, la disposición rítmica de las pasiones y la disposición de las isotopías.

11 Son pioneros, en este sentido, los trabajos de Mojezko da Costa (1984) y Thürleman (1980). 
En otros trabajos, he estudiado la representación enunciva y los juegos que propone al enunciatario (Usandizaga, 1992), y he tratado de profundizar en el componente pasional de estos juegos (Usandizaga, 1999) para estudiar su correspondiente efecto rítmico y tonal, y por lo tanto enunciativo; pero, en este análisis, pretendo dar algunos ejemplos de la disposición de las isotopías, algo en cierto modo previo a las otras disposiciones. Tal vez lo anterior sea más bien la desembocadura del proceso, y haya que empezar por detectar el ritmo semántico ligado a la organización de las isotopías, para a continuación ver cómo se proyectan sujetos, tiempos y espacios en el enunciado, y cómo estos juegos narrativos y discursivos afectan a la instancia de la enunciación, pero considerando no sólo el nivel de la acción y de lo cognitivo, sino también en el nivel pasional; un nivel pasional que genera efectos no solamente referidos a la actitud del enunciador, sino también efectos rítmicos ${ }^{12}$. Este conjunto puede ayudar a recorrer analíticamente el trayecto propuesto.

\section{LA DISPOSICIÓN DE LAS ISOTOPÍAS}

No está de más recordar aquí lo que guía estas reflexiones: si el ritmo (la dirección tensiva) y el tono (la actitud hacia el enunciado) están evidentemente, sobre todo el primero, relacionados en el plano de la expresión con el mundo natural y la mediación perceptiva del cuerpo, algo parecido ocurre en el plano del contenido, y la disposición de las isotopías no es ajena a esto. Las isotopías, por ejemplo, no son para Zilberberg (1988: 160-162) una simple iteración de semas, sino una dinámica orientada que puede marcar la aspectualización «saillante»y «passante». Cada nivel de segmentación (y de articulación) debe presentar su «cifra rítmica»; hay que aprehender ritmos intersecuenciales, o, en última instancia, coextensivos del discurso entero (179). Así, la continuidad o interrupción de las isotopías marca un ritmo que va acompañado por otro lado de las tensiones entre niveles (por ejemplo, entre los diferentes tipos de sujeto). Todo ello tiene que ver con la construcción de la dirección, de la espera, y con su distensión.

12 He tratado de estudiar los efectos rítmicos y tonales de la disposición pasional (Usandizaga, 1999). 
Como decíamos, Zilberberg (1988), quien reclama la consideración del poema como goce (136), ha estudiado los juegos de isotopías como algo rítmico, porque provocan efectos de sentido que se pueden leer según el esquema de pregunta/ respuesta o apertura/ cerrazón. Por ejemplo, propone un acercamiento rítmico al verso: la escisión del alejandrino según $6+6$ puede proponer, entre los dos hemistiquios, ya sea una relación contractual del tipo pregunta respuesta, o una relación de competición entre cesura y fin de verso (146). Pero, yendo más allá, se pregunta qué ocurre cuando una isotopía se interrumpe para dejar paso o dejar hablar a una segunda: «¿qué le pasa, a «dónde» va la primera?» (171). Su respuesta tiene que ver con el concepto de tensión: «Esta interrogación, en la perspectiva hjelmsleviana del sincretismo, cambia de significación: la primera isotopía puede pasar al estado latente cuando se desarrolla la segunda $\longrightarrow$ o a la inversa— (171). Su tesis, para el poema estudiado («Larme», de Arthur Rimbaud), es que se produce una especie de salto que se hace necesario por el contenido mismo tratado en el poema, el valor, en el que se entrecruzan dos esfuerzos distintos: el que tiene que ver con el objeto de valor y el que tiene que ver con el valor del valor (171). Zilberberg (198) clasifica estos efectos según la figuralidad o figuratividad en que se sitúan, y según la dimensión evaluativa, cognitiva o pragmática; dentro de estas clasificaciones cruzadas, habla de tensividad (tensión/ distensión), de espacialización (cerrado/ abierto), de objetivación (disyunción/ conjunción); de temporalización (esperado/ acontecido), de cognición (no sabido/ sabido), de alienación (carencia/ satisfacción).

Los términos de Zilberberg pueden ilustrarse con el análisis de un poema de Rubén Darío, «Yo persigo una forma...», que es el último poema de Prosas profanas, publicado en 1896 y reeditado en 1901 con la adición de 21 poemas:

Yo persigo una forma que no encuentra mi estilo, botón de pensamiento que busca ser la rosa; se anuncia con un beso que en mis labios se posa al abrazo imposible de la Venus de Milo.

Adornan verdes palmas el blanco peristilo;

los astros me han predicho la visión de la Diosa;

y en mi alma reposa la luz como reposa

el ave de la luna sobre un lago tranquilo.

Y no hallo sino la palabra que huye,

la iniciación melódica que de la flauta fluye

y la barca del sueño que en el espacio boga;

y bajo la ventana de mi Bella-Durmiente,

el sollozo continuo del chorro de la fuente

y el cuello del gran cisne blanco que me interroga. 
La tensión semántica del poema de Darío es simple pero eficaz: la contradicción se plantea ya entre los dos hemistiquios del primer verso: la secuencia carencia / satisfacción (que se acompaña de otras como esperado / acontecido) se resuelve negativamente; el segundo verso incide en el aspecto cerrado/ abierto de la contradicción. Entre el segundo par de versos del primer cuarteto se repite una estructura parecida a la del primer verso: si bien el primero parece indicar la satisfacción de la carencia (el beso que se anuncia), el segundo recalca el carácter imposible del abrazo. De nuevo, la oposición no resuelta se repite entre el segundo cuarteto y el primer terceto, insistiendo en la oposición esperado / acontecido y retomando la idea de «forma», es decir, de lenguaje adecuado a la intuición, a la percepción profunda, a la visión, para subrayar el carácter imposible de esa adecuación en el primer terceto. El último terceto es una afirmación de la permanencia de la carencia que se hace fluir expresivo y a la vez pregunta no respondida. Así, este trayecto corresponde al cuestionamiento de algo que en otros poemas de Darío se presenta como resuelto: la adecuación entre el lenguaje y la expresión poética, lo que a la vez implica el cuestionamiento de la armonía del universo en correspondencia con el hombre («Eres un universo de universos / y tu alma una fuente de canciones», decía en cambio en «Ama tu ritmo...», también de Prosas profanas. Este último poema del libro habla pues de la insuficiencia del lenguaje para expresar el infinito y lo ideal, que sólo pueden ser sugeridos, pero el trayecto nos hace recorrer la contradicción, y no sólo concebirla.

Resulta interesante observar aquí que un tercer poeta peruano, Emilio Adolfo Westphalen (1988), retiene de su lectura de Trilce (1922), de Vallejo, más allá de las referencias familiares y católicas que no le son simpáticas, «la enorme tensión afectiva que hacía sentir cada poema como un puñado de nieve arrojado en pleno rostro. Igualmente me admiraba comprobar cómo la construcción del poema se mantenía siempre sólida a pesar de los grandes desniveles entre sus elementos, de esas «caídas de arquitecto» en las que Vallejo se ha mostrado perseverante a lo largo de toda su obra» (734). Westphalen (735) intuye que

el salto brusco se debía a un cambio del sistema de codificación empleado. El poema se ajustaba a una clave, mas de repente el poeta acudía a otra, distinta y hasta opuesta. El juego era a veces el simple reemplazo de una antinomia por otra, aunque a menudo alguno bastante inesperado. Se sentía esa pesada mano del destino desbaratando todo esfuerzo humano, al que ama referirse Vallejo. Más extraño sin embargo era que a pesar del trastorno el poema no sólo permanecía intacto, sino que aumentaba en vigor y significado por esa intromisión. 
Westphalen conjetura que, más que al uso de las palabras aisladas fuera de su contexto que propone Vallejo, la eficacia del procedimiento «depende exclusivamente de la distancia entre el significado común y el que pueda trasvasarle para la ocasión el poeta. Allí nace justamente la tensión, la gran fuerza expresiva que el choque con lo inusitado suscita» (735). El poeta explica, pues, la tensión del poema gracias a esos cambios de isotopías especialmente logrados en Vallejo. Si observamos un conocido poema de Los heraldos negros (publicado en 1918), «Idilio muerto», veremos cómo la estructura que propone el poema se resuelve de un modo más profundo en el juego de las isotopías:

\footnotetext{
Qué estará haciendo esta hora mi andina y dulce Rita de junco y capuli; ahora que me asfixia Bizancio, y que dormita la sangre, como flojo cognac, dentro de mí.
}

Dónde estarán sus manos, que en actitud contrita planchaban en las tardes blancuras por venir; ahora, en esta lluvia que me quita las ganas de vivir.

Qué será de su falda de franela, de sus afanes, de su andar; de su sabor a cañas de mayo del lugar.

Ha de estarse a la puerta mirando algún celaje, y al fin dirá temblando: "Qué frío hay... Jesús!». Y llorará en las tejas un pájaro salvaje.

El poema de Vallejo plantea una estructura de pregunta / respuesta: las tres primeras estrofas desarrollan la pregunta, y la última centra la respuesta. La misma amplitud de la pregunta señala la importancia de la evocación nostálgica que en realidad es, del mismo modo que la respuesta, en realidad una suposición («Ha de...»), remite al escenario de la memoria. Pero más allá de la estructura explícita tensión / distensión que acompaña sin duda la entonación verbal del poema, son los juegos de isotopías los que producen la tensión del poema: dentro de la misma pregunta se plantea un juego de isotopías contradictorias, sobre todo centrado en la oposición naturaleza / arte, y en la respuesta se genera otra isotopía que las trasciende. Julio Ortega (1988), que subraya además las fuertes simetrías gramaticales y métricas y la coexistencia de lo escritural y lo coloquial, ha estudiado cómo este poema contrapone desde la primera estrofa dos sujetos con valores distintos: «ella», ligada a la naturaleza y a lo rural, frente a «yo», ligado al arte y a lo urbano. La segunda estrofa contrapone el hogar a la errancia, y a la vez 
inaugura una isotopía, la del «sinsabor»; ambas se contraponen a la identidad y el sabor de la tercera estrofa, centrada en «ella». La distensión se centra aparentemente en la cuarta estrofa, en el paisaje recobrado en el recuerdo, y en la respuesta hipotética, centrada en el hogar. Pero la última frase resuelve las antítesis arte / naturaleza y hogar / errancia más allá de lo rural y lo urbano: en lo literario y a la vez lo natural: «Y llorará en las tejas un pájaro salvaje», con sus ecos fuertemente whitmanianos. «En este emblema», dice Ortega (614), «se proyecta el poeta como parte del paisaje recobrado, pero libre de su domesticidad». El complejo sistema temporal del poema combina también pasado, presente y futuro, y, como señala Ortega «su escritura coincide con su enunciación» (614); podríamos decir que se produce un embrague enunciativo, que reunifica para la lectura los tiempos y los sujetos. Lo importante para Ortega es que esa resolución se da como una especie de negociación entre la visión o la figuración literarias y el coloquio de lo cotidiano: «Por eso, las antítesis sólo pueden resolverse en una figura de equivalencia: en la visión o entrevisión que el poema actualiza, recobrando el habla misma de la amada perdida gracias al Coloquio que el Arte suscita en la Figuración» (615).

El poema de Vallejo, como veíamos, ostenta una estructura tensiva nítida, si bien la trasciende con el juego de isotopías. Consideremos para acabar un caso más complejo, puesto que la lectura proyecta una estructura latente poco convencional. Se trata de «Esposa sepultada», de Eielson (1998), un cuarto poeta peruano, y que corresponde a su libro Reinos (escrito en 1944):

\footnotetext{
Encerrado en tu sombra, en tu santa sombra, Con el agua en las rodillas, te pregunto

¿Es el peso del manzano, clavetado de estrellas, Sobre mi corazón oscuro, o eres tú, cabeza Fugitiva de las horas, novia mía enterrada, La que arrastras tu cabellera incesante Como una botella rota, por entre mi sangre?

Yo no sé, señora mía, luto de mi amor,

Si eres tú la que reinas sobre tanta ceniza,

$O$ si es sólo tu sombra, tu velo de novia en el aire,

Poblado de perlas, naves y calaveras-

El que inunda mi alcoba, igual que un océano.
}

El poema de Eielson, en efecto, tiene una estructura evidente mucho menos explícita en cuanto a una tensión / distensión indicada por la forma gramatical o prosódica, pues se propone una disyuntiva que no se aclara ni en la pregunta ni en la respuesta, y permanece el desgarra- 
miento y la separación de esa pregunta circular y sin respuesta. Sin embargo, el componente rítmico del poema es muy fuerte; parece escrito con una partitura de fondo, y algo así señala el propio Eielson cuando habla en una entrevista de la «matriz musical» a partir de la que escribe sus poemas: «muchos de mis poemas, casi todos, sobre todo los más viejos, han nacido de esa manera y casi sin ser tocados ni corregidos» (Zapata, 1987-88: 95) ; y añade: «En ese sentido es la matriz musical la que me ha ayudado muchísimo, que salía sin el menor esfuerzo» (96).

Más que su desarrollo secuencial, tal vez sea útil, en este caso, detectar, en primer lugar, el centro del poema —el centro de significación, que coincide casi con su centro geométrico-, y que parece ser la referencia a dos sujetos: «la que arrastras tu cabellera incesante/ como una botella rota, por entre mi sangre» y «mi corazón oscuro», pues la pregunta es sobre la naturaleza de esa presencia en la percepción del sujeto que habla en el poema. Es la obsesión del dolor, el recuerdo y el paso del tiempo que se manifiestan como pregunta sin respuesta, como una eterna pregunta circular que es, en definitiva, un obsesivo juego de isotopías; al centro, mi corazón oscuro, el sujeto como englobado, «encerrado en tus sombra», rodeado por la sombra e invadido por el agua; en su interior, otro elemento englobado, la botella rota lacerando; al final, se vuelve a lo englobante, la sombra que inunda la alcoba. La pregunta en realidad, como decíamos, es sobre la naturaleza de lo que invade, penetra y rodea al sujeto: el signo, la visión - el peso del manzano, la sombra, el velo de novia - o bien la persona, «tú», novia mía enterrada, señora mía, luto de mi amor. El poema de Eielson, así, permanece como un sistema de tensiones que no siguen una linealidad, sino que actúan como presiones a partir de un centro, hacia el interior y hacia el exterior del sujeto; el centro es el dolor y la carencia interiorizados y a la vez rodeando al sujeto. Lo que percibe nuestro cuerpo al leer este poema, construido con la peculiar maestría rítmica de Eielson, es circular como la circulación de la sangre o el encerramiento. Así, la tensión no se resuelve, pero ése es justamente el componente significativo de este trayecto, propio de la primera época poética de Eielson. En esta primera época la muerte reina tras la majestuosa belleza del mundo: el yo se presenta como separado del universo; entre los astros y la ceniza ve desmoronarse el cosmos, porque esa belleza es, más que florecimiento, incendio. Y ese incendio grandioso y melancólico parece alimentado por lo oculto y aun lo enterrado: la esposa sepultada, la reina enterrada son en este libro figura recurrente que suscita el canto elegíaco por un mundo en destrucción cuya materia se convierte solemnemente en ceniza. 
Un análisis más profundo de los juegos del texto confirmaría lo que aquí se apunta: que los núcleos significativos de los diversos poemas no son ideas traducibles y parafraseables, sino trayectos de lectura, a la vez somáticos, cognitivos y pasionales.

\section{Referencias bibliográficas}

ADÁN, M. (1988). Antología, edición de Mirko Lauer. Madrid: Visor.

Alonso, A. (1954). Poesía y estilo de Pablo Neruda. Buenos Aires: Losada. BALlART, P. (1998). El contorn del poema. Barcelona: Quaderns Crema.

CoQueT, J.-Cl. (1972). «Poétique et linguistique». En Essais de sémiotique poétique, A. J. Greimas (ed.), 26-44. París: Larousse.

Darío, R. (1952). Poesías, ed. de Ernesto Mejía Sánchez, prólogo de Enrique Anderson Imbert. México: FCE.

DORRA, R. (1997). «Le souffle et le sens». En Lire Greimas, E. Landowski (ed.), 185-201. Limoges: PULIM.

Eielson, J. E. (1998). Poesía escrita, ed. de Martha L. Canfield. Santafé de Bogotá: Norma.

Eco, U. (1979). Lector in fabula. Barcelona: Lumen, 1981.

FABBRI, P. (1992). «Échappée». Nouveaux Actes Sémiotiques 19, 19-30.

Fontanille, J. (1992). «Des états de choses aux états d'âme (suite)». Nouveaux Actes Sémiotiques 20, 1-8.

- (1987). Le savoir partagé: théorie de la connaissance chez Marcel Proust. París-Amsterdam-Philadelphia: Hadés-Benjamins.

- (1998). Sémiotique du discours. Limoges: PULIM.

Fraisse, P. (1956). Les structures rythmiques. París-Bruselas: Publications Universitaires de Louvain-Erasme.

Greimas, A. J. (1972). «Pour une théorie du discours poétique». En Essais de sémiotique poétique, A. J. Greimas (ed.), 5-24. París: Larousse.

- (1984). «Sémiotique figurative et sémiotique plastique». Actes Sémiotiques (Documents) VI, 60, 5-24.

- (1986). Maupassant. La semiotique du texte: exercices pratiques. París: Seuil.

- (1987a). «Algirdas Julien Greimas mis à la question». En Sémiotique en jeu. A partir et autour de l'oeuvre d'A.J. Greimas, M. Arrivé y J. C. Coquet (eds.), 301-330. París-Amsterdam-Philadelphia: Hadès-Benjamins.

- (1987b). De l'imperfection. Périgueux: P. Fanlac.

Greimas, A. J. y Courtés, J. (1979). Sémiotique. Dictionnaire raisonné de la théorie du langage, vol I, 90-91. París: Hachette.

GrEIMAS, A. J. y otros (1986). Sémiotique. Dictionnaire raisonné de la théorie du langage, vol. II. París: Hachette. 
Greimas, A. J. y Fontanille, J. (1991). Sémiotique des passions. Des états de choses aux états d'âme. París: Seuil.

JAKoBSON, R. (1963). «Linguistique et poétique». En Essais de linguistique générale, 209-248. París: Minuit.

- (1980). Dialogues. París: Flammarion. Trad. esp., Lingüística, poética, tiempo. Conversaciones con Krystina Pomorska. Barcelona: Crítica, 1981.

Mozejko da Costa, D. T. (1984). «Énoncé et énonciation». Actes Sémiotiques (Documents) VI, 52, 5-19.

MANGini GonZÁleZ, Sh. (1980). Gil de Biedma. Madrid: Júcar.

MeschonNic, H. (1982). Critique du rhytme. Anthropologie historique du langage. París: Verdier.

ORTEGA, J. (1988). «La hermenéutica vallejiana y el hablar materno». En César Vallejo. Obra poética, A. Ferrari (ed.), 606-620. Madrid: CSIC.

OUELLET, P. (1992). «Signification et sensation. La représentation sémiolinguistique du sensible». Nouveaux Actes Sémiotiques 20, 1-33.

PAZ, O. (1956). El arco y la lira. México: FCE.

Smith, B.H. (1968). Poetic Closure. A Study of how Poems End. Chicago: The University of Chicago Press.

SPIRE, A. (1949). Plaisir poétique et plaisir musculaire. París: Corti.

Tomatis, A. (1978). L'oreille et le langage. París: Seuil.

Rowe, William (1998). «No hay poesía latinoamericana, lo que hay son múltiples vertientes». Diaspora 1, 119-21.

ThürlemanN, F. (1980). «La fonction de l'admiration dans l'esthétique du XVII ${ }^{\mathrm{ème}}$ siècle». Actes Sémiotiques (Documents) 11, 9-39.

USANDIZAGA, H. (1992). «Poetic Discourse and Enunciative Distance/Discours poétique et distance énonciative». En Signs of Humanity/L'homme et ses signes, G. Deledalle (ed.), 215-220. Berlín: Mouton-De Gruyter.

- (1999). «El ritmo semántico. A propósito de un poema de Oliverio Girondo». Cuadernos de Lengua y Habla 1, 131-155.

VAlente, J. A. (1998). «Memoria personal, colectiva, de la materia. Entrevista con José Ángel Valente», entrevista de Mario Campaña. Ajoblanco 107, 52-57.

VAllejo, C. (1973). «Electrones de la obra de arte». En El arte y la revolución, 69-71. Lima: Mosca Azul.

- (1990). Obra poética completa. Madrid: Alianza.

WestPhalen, E. A. (1988). «Testimonios y juicios sobre César Vallejo y su obra poética». En César Vallejo, Obra poética, Américo Ferrari (ed.), 734736. Madrid: Archivos.

WRIGHT, Ch. (1998). «Narrativa de la imagen (Una correspondencia con Charles Simic)». Hueso Húmero 33, 130-149.

ZAPATA, M. A. (1987-88). «Matriz musical de Jorge Eduardo Eielson» (entrevista). Inti. Revista de Literatura Hispánica 26-27, 93-100.

Zilberberg, Cl. (1988). Raison et poétique du sens. París: PUF. 